\title{
EXPERIMENTAL EVALUATION OF BALL BAR STANDARD THERMAL PROPERTIES BY SIMULATING REAL SHOP FLOOR CONDITIONS
}

\author{
Klobucar, R. \& Acko, B. \\ University of Maribor, Faculty of Mechanical Engineering, Smetanova 17, SI-2000 Maribor, Slovenia \\ E-Mail: rok.klobucar@um.si,bojan.acko@um.si
}

\begin{abstract}
Monitoring quality of production processes is a complex task consisting of different measurements of product properties and process parameters, as well as visual checks and other activities. One of the most important measurement tasks is measuring complex product geometry. In order to get information about measured quantities as quickly as possible, measurements are made directly on the shop floor. However, assuring traceability of complex co-ordinate measurements in uncontrolled shop floor conditions is an advanced metrological task requiring special measurement standards and procedures. European project EMRP IND62 TIM that was agreed between EC and European metrology association Euramet is aimed to introduce a traceability chain into in-process geometrical measurements by offering different solutions for calibrating machine tools in harsh environmental conditions. One of the tasks of this project was to develop a highly accurate robust 1D measurement standard with very low expansion coefficient. The article presents basic design of this standard and experimental verification of its thermal expansion characteristics in a laboratory, as well as in harsh environment in production companies. Thermal expansion verification was performed by means of measurements on a co-ordinate measuring machine at different temperatures simulating real shop floor conditions.

(Received in December 2015, accepted in March 2016. This paper was with the authors 1 month for 1 revision.)
\end{abstract}

Key Words: Traceability, Co-Ordinate Measurement, Measurement Standard, Thermal Expansion

\section{INTRODUCTION}

Quality of manufacturing processes is an essential element for assuring overall product quality. It is assured through organisational, executing and monitoring activities [1-4]. Most commonly applied process monitoring activities are measurements of product geometry and visual checks [5]. One of the most important measurement tasks is measuring complex product geometry. In order to get information about measured quantities as quickly as possible, measurements are made directly on the shop floor.

The principle of in-process metrology is to obtain measurement data directly in the manufacturing process and to use them for effective process control. One prerequisite to significantly improve the manufacturing processes is the incorporation of traceable dimensional metrology directly on machine tools.

Achieving traceable and reliable dimensional measurements on the shop floor requires material measurement standards that are deployable on machine tools and are robust and nonsusceptible to the environmental conditions. Control of thermo-mechanical errors on a machine tool is not the responsibility of the machine tool manufacturers alone. Machine tool end-users require qualified and calibrated measurement standards and procedures for guiding them to mitigate, control and correct the errors. Neither the machine tool manufacturers nor the end-users have currently no suitable stable standards available for performing corrections in real-life machining conditions. Furthermore, existing standards for CMM calibration do not adequately address the environmental conditions on the shop floor. Therefore, there is an urgent need for a new generation of robust material standards with corresponding procedures 
and guidelines for the assessment of machine tool measurement performance directly on the shop floor [6].

\section{INTRODUCTION OF THE BALL BAR STANDARD}

The purpose of the ball bar standard is to check geometrical properties of machining centres with various production volumes (up to $3 \mathrm{~m}$ per axis) and various numbers of axes [7,8]. The metrological check is to be performed with no load. As a result, metrological check is returning machine tool compliance with specification (maximum permissible errors - MPEs). No error mapping like in some other traceability approaches $[9,10]$ is expected to be performed by using the metrological results. The machining centre under test shall be equipped with a tactile probing system attached to the machine (normally in the tool holder).

The performance test should be executed in the main axes $(x, y, z)$ and optionally also in spatial diagonals [8]. Up to 4 different lengths (500 mm, $1000 \mathrm{~mm}, 1500 \mathrm{~mm}$ and $2000 \mathrm{~mm}$ ) in different axial or spatial positions are to be measured [11, 12]. The deviations are calculated as measured values (measured by the machine tool) minus calibrated distances between ball centres.

\subsection{Probing surfaces}

Probing elements (balls) are made of ceramics. Since the standard is intended to be used for calibrating contact (tactile) measurement systems, surface appearance (shining/non-shining) is not of big importance. The most important feature is spherical shape. The ceramic balls were purchased from a commercial provider based on experiences from the past. The maximum allowable deviation of sphericity is $0.5 \mu \mathrm{m}$. Surface features of other constructional parts have no influence on metrological properties of the standard.

\subsection{Materials of construction elements}

Different materials are used for different constructional parts of the standard. The materials of the main constructional parts are listed below:

- Main body (tube) - composite material (carbon fibres in epoxy matrix),

- Bases (joints) - steel,

- Ball holders - steel,

- Compensator for thermal expansion - aluminium,

- Probing balls - ceramics.

Materials were chosen on the bases of experiences with similar standards. Temperature expansions, resistance against liquids (water, oils ...), bending, and surface properties (probing elements) were considered while choosing materials.

Table I presents the coefficients of linear thermal expansion of different materials used for the ball bar standard.

Composite material was chosen for the main body of the standard because of its rigidity, low temperature expansion and low weight (the standard should be easily transportable). Alternative material for the main body of the standard would be e.g. invar, which has similar properties as regards metrology (expansion, bending), but would be heavier and much more expensive. The ceramic material for probing balls has almost no equivalent alternative as regards surface properties (sphericity, hardness, resistance against liquids) and is therefore used worldwide in similar cases. Stainless still was chosen for all coupling elements due to its resistance to corrosion and machining properties. Economic aspects were considered as well. Aluminium is used for the "temperature compensator" due to appropriate temperature expansion coefficient, which can be precisely determined. 
Table I: Coefficients of linear thermal expansion (CLTE) of applied materials.

\begin{tabular}{|c|l|l|c|}
\hline Position & Part name & Material & $\begin{array}{c}\text { CLTE } \\
\left(\times 10^{-6} \mathrm{~K}^{-1}\right)\end{array}$ \\
\hline 1 & Tube 1 & Graphite/epoxy & 2.2 \\
\hline 2 & Tube 2 & Graphite/epoxy & 2.2 \\
\hline 3 & Tube 3 & Graphite/epoxy & 2.2 \\
\hline 4 & Base 1 & Mat. No. 1.4112 & 9.8 \\
\hline 5 & Base 2 & Mat. No. 1.4112 & 9.8 \\
\hline 6 & Base 3 & Mat. No. 1.4112 & 9.8 \\
\hline 7 & Ball holder & Mat. No. 1.4112 & 9.8 \\
\hline 8 & Flanche & Mat. No. 1.4112 & 9.8 \\
\hline 9 & Ball holder 500 & Mat. No. 1.4112 & 9.8 \\
\hline 10 & Ball holder 1000 & Mat. No. 1.4112 & 9.8 \\
\hline 11 & Ball holder ext. & Mat. No. 1.4112 & 9.8 \\
\hline 12 & Compensator tube 500 & Al. 6061-T6 & 23.6 \\
\hline 13 & Compensator tube 1000 & Al. 6061-T6 & 23.6 \\
\hline 14 & Compensator tube ext. & Al. 6061-T6 & 23.6 \\
\hline 15 & Compensator nut & Mat. No. 1.4112 & 9.8 \\
\hline 16 & Holder 1 & Mat. No. 1.4112 & 9.8 \\
\hline 17 & Nut-M6 & Mat. No. 1.4112 & 9.8 \\
\hline 18 & Holder 2 & Mat. No. 1.4112 & 9.8 \\
\hline 19 & Probing ball & Alumina oxide $\mathrm{Al}_{2} \mathrm{O}_{3}$ & 8.1 \\
\hline
\end{tabular}

\subsection{Design}

The standard consists of three modules. Two modules (1 and 2) are ball bar standards of different lengths (module $1-500 \mathrm{~mm}$, module $2-1000 \mathrm{~mm}$ ) that can be used separately or in combination with module 3 (which is only an extension and can't be used separately). Each module contains a "temperature compensator", which compensates thermal expansion of the composite tube (main body of the standard). Detailed design of modules 1 and $2[11,12]$ is shown in Fig. 1.

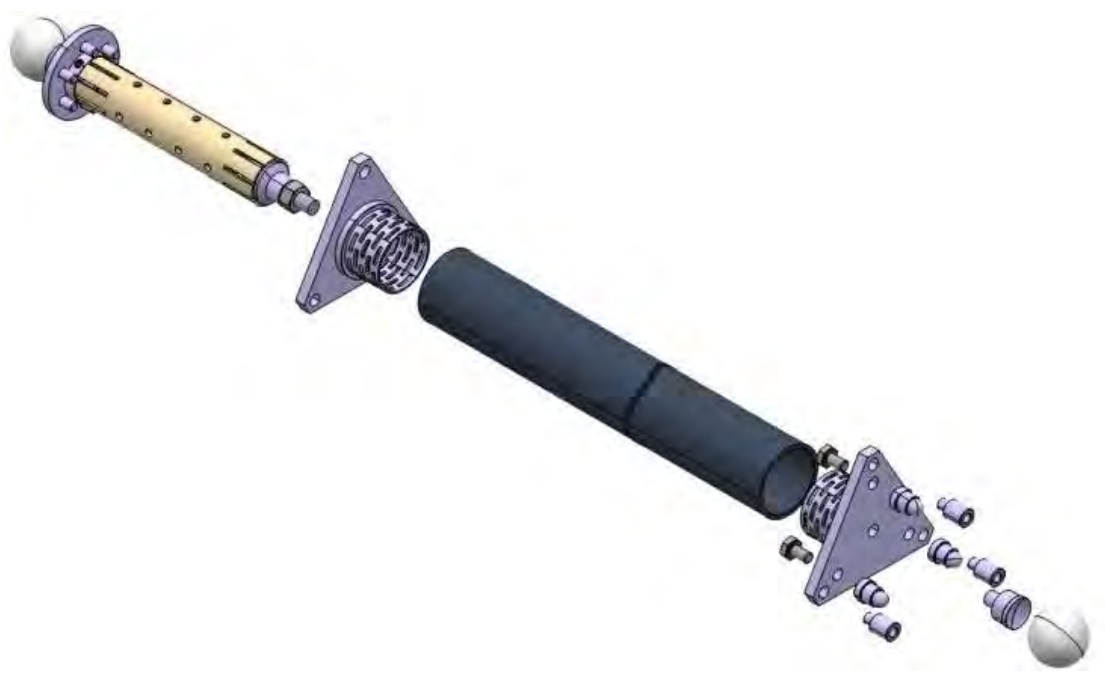

Figure 1: Design of modules 1 and 2.

As can be seen in Fig. 1, the design of the "relative simple" standard is quite complex. There are several constructional parts made of different materials. For later thermal expansion error separation it is very important to consider exact dimensions of each constructional part. The dimensions of modules 1 and 2 are shown in Fig. 2. 

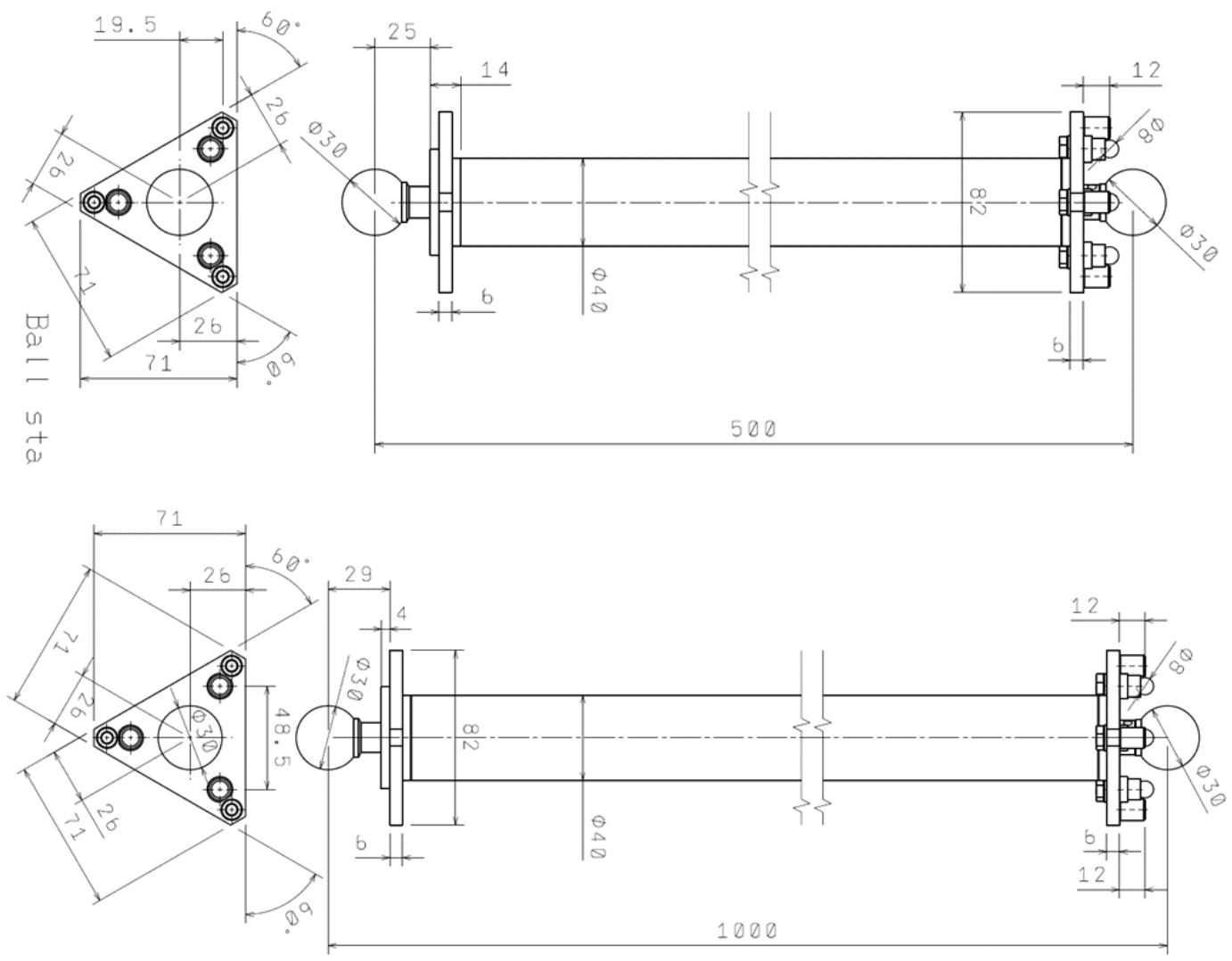

Figure 2: Dimensions of modules 1 and 2.

In order to achieve length stability in harsh environmental conditions, the standard is equipped with an active thermal expansion compensator (Fig. 3).

The compensator is made of two different materials with significantly different thermal expansion coefficients. The tube (Pos. 12, 13, 14 in Fig. 3) is made of aluminium, while the flange (Pos. 8), the ball holders (Pos. 9, 10, 11), the tube cover (Pos. 15), and the nut (Pos. 26) are made of stainless steel. The flange (Pos. 8) is attached to the composite tube - main body of the standard $[11,12]$.



Figure 3: Design of the thermal expansion compensator. 


\subsection{Traceability}

Metrological characteristics of the standard are available in the form of a calibration certificate, stating 4 distances between line centres (at nominal values $500 \mathrm{~mm}, 1000 \mathrm{~mm}$, $1500 \mathrm{~mm}$, and $2000 \mathrm{~mm}$ ). The data are available in paper as well as in electronic form.

The standard is being calibrated by using tactile CMM ZEISS UMC 850 that is traceable to the national standard of length [13]. Three modules are calibrated separately by applying normal calibration procedure (probing balls in at least 20 points each, repeating measurements 5 times for each distance, calculating average distances and standard deviations). The ball distances on combined modules are calculated by considering geometrical properties of joints between the modules.

The standard is being calibrated with expanded uncertainty $U=2.1 \mu \mathrm{m}+3.3 \cdot 10^{-6} \cdot \mathrm{L}$ $(k=2$; level of confidence $95 \%)$. Stated uncertainty [14] is expanded uncertainty given by the CMM producer and checked by a verification test. The uncertainty has been proved by an interlaboratory comparison [15] within the project.

\section{THERMAL STABILITY OF THE STANDARD}

\subsection{Expectations}

Metrological stability of the standard in terms of ball distance changes is expected to be less than $1 \mu \mathrm{m} /$ year. More critical feature could be length change due to bending and compression under different conditions of use (single module, combined modules, position in space horizontal, vertical, spatial angle). Preliminary research was performed by using finite element method. The results have shown that the maximum expected error in terms of ball distance change was within $2 \mu \mathrm{m}$.

\subsection{Conceptual solution}

For meeting expectations, especially in harsh environmental conditions in shop floor, two technical measures were taken:

- The main body of the standard is made of composite material (carbon fibres in epoxy matrix) with low thermal expansion coefficient;

- The standard is equipped with a thermal expansion compensator, described in section 2.3.

The second measure was necessary due to incomplete knowledge of a thermal expansion coefficient of the composite material. While theoretical data in handbooks state values between $2 \cdot 10^{-7} \mathrm{~K}^{-1}$ and $6 \cdot 10^{-7} \mathrm{~K}^{-1}$, our experimental analysis of the used material has shown $\alpha \approx 2 \cdot 10^{-6} \mathrm{~K}^{-1}$. The principle of the thermal expansion compensator is shown in Fig. 4. The flange (Fig. 3 Pos. 8) is attached to the composite tube - main body of the standard. If the ambient temperature is increased, the composite tube is expanding in "positive" direction, while the aluminium tube is expanding in the opposite direction and pulls the ceramic ball (Fig. 3 - Pos. 19) inside the main body of the artefact.

The compensation depends on the accuracy of calculating lengths, as well as thermal expansions of the main body and the compensator parts. However, since the thermal expansion coefficients of the used materials are not exactly known, those calculations are not very accurate. Therefore, experimental expansion evaluations and length corrections of the aluminium part in numerous iterations were needed. 


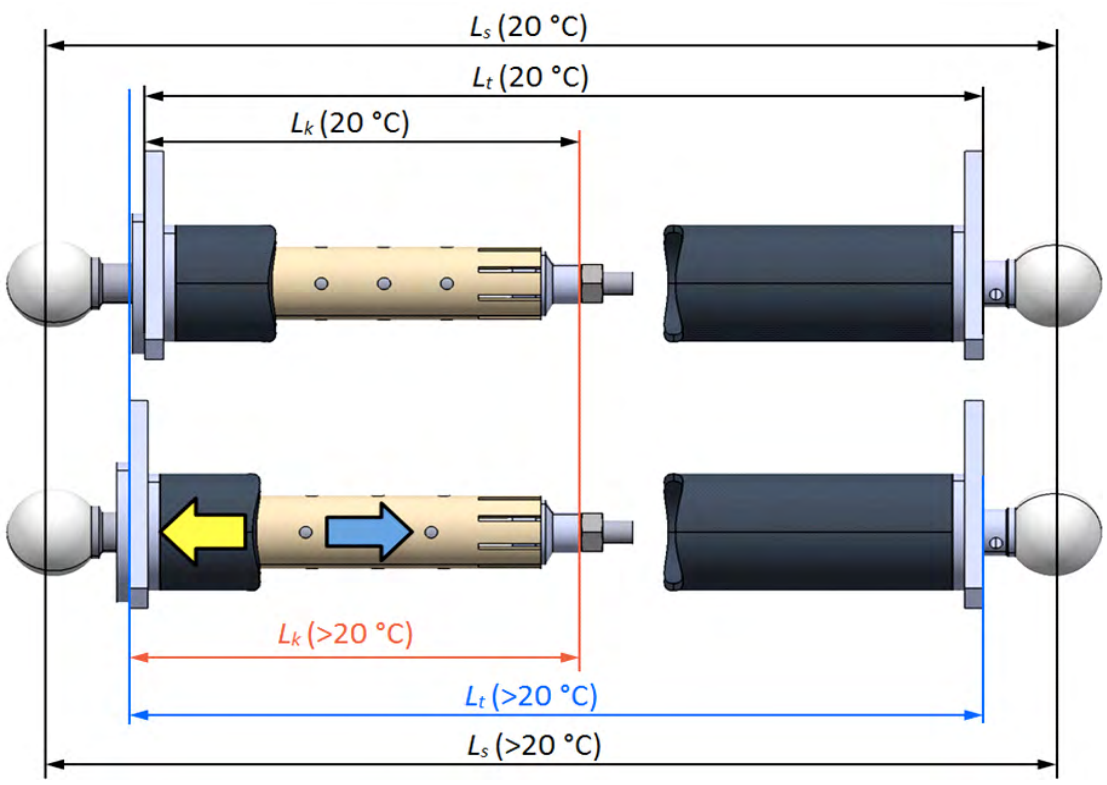

Figure 4: Thermal expansion compensator - principle of operation.

\section{VERIFICATION OF THERMAL STABILITY BY SIMULATIONS}

Thermal expansion of the standard has been investigated through three research phases:

- Simulation of numerous temperature situations and prediction of thermal expansion by using finite element analysis,

- Experimental thermal expansion evaluation by simulating real shop floor environmental conditions in the Laboratory for Production Measurement,

- Experimental measurements in real shop floor conditions in companies EMO Orodjarna and Gorenje Orodjarna.

The third phase was executed in numerous steps at different shop floor conditions in order to confirm outcomes of theoretical and experimental simulations. These measurements served also for validating verification procedures for machine tools.

\subsection{Simulation of temperature variation and finite element analysis}

This investigation was performed in order to predict the time necessary for temperature homogenization through entire standard. The main problem of the thermal compensator is namely its enclosure in the composite tube.

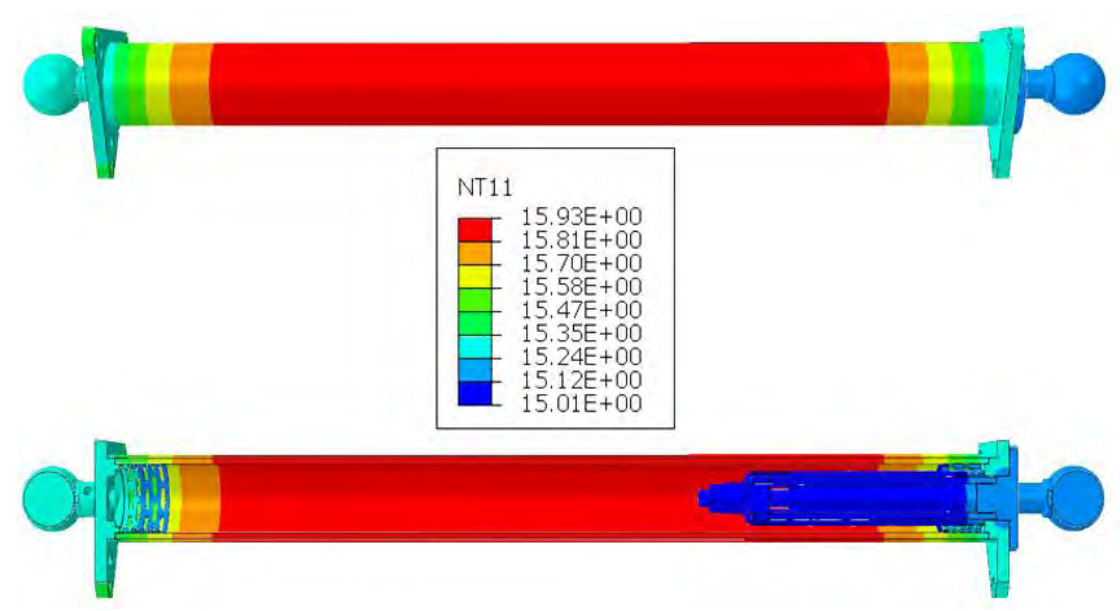

Figure 5: Temperature distribution on the standard at $15^{\circ} \mathrm{C}$. 
The simulation was performed for module $500 \mathrm{~mm}$. It was started with temperature $T=15^{\circ} \mathrm{C}$ and was changed slowly to $T=22{ }^{\circ} \mathrm{C}$. The heating time was set to 20 minutes, while the air heat transfer coefficient was set to $5 \mathrm{~W} / \mathrm{m}^{2} \mathrm{~K}$. Fig. 5 illustrates the temperature distribution on the surface and in the standard cross-section. Central part of the standard is the warmest, while both ends (ceramic balls) have approximately the same temperature. However, already in this early stage of the experiment it can be seen that the compensator inside the tube is the coolest part of the artefact (cross-section view).

Through different phases of raising temperature it can be seen that the left part of the standard (without thermal expansion compensator) is heating faster than the right side. Finally, at $T=22{ }^{\circ} \mathrm{C}$ after approximately 20 minutes, the left part of the standard reaches homogenous temperature, which is equal to the air temperature, while the right side is much cooler. This situation is illustrated in Fig. 6.

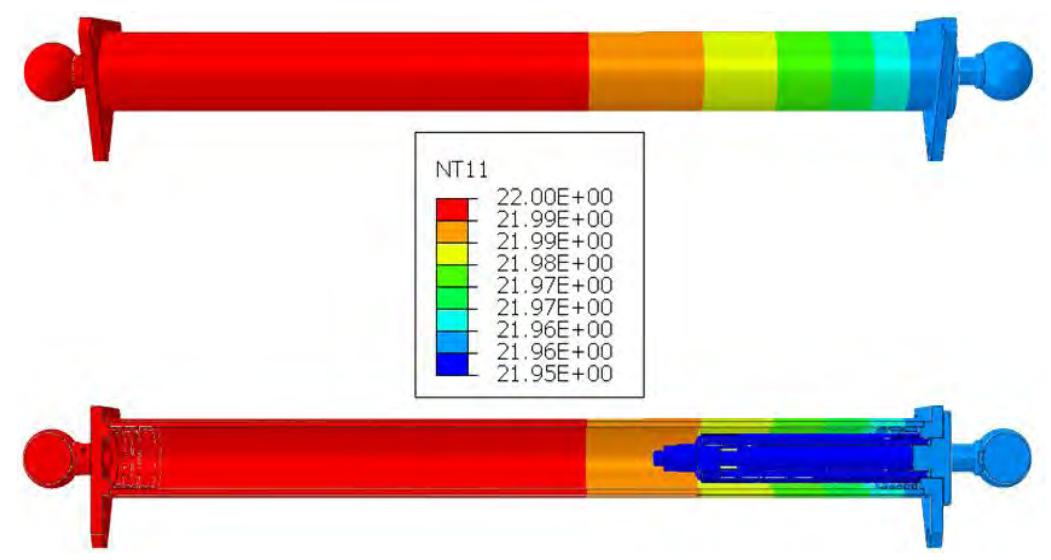

Figure 6: Temperature distribution on the standard at $22^{\circ} \mathrm{C}$.

The simulation continued until the temperatures through the entire standard were homogenuous. Fig. 7 shows heating time of the most important constructional parts of the ball standard $500 \mathrm{~mm}$ from $T=15^{\circ} \mathrm{C}$ to $T=22^{\circ} \mathrm{C}$.

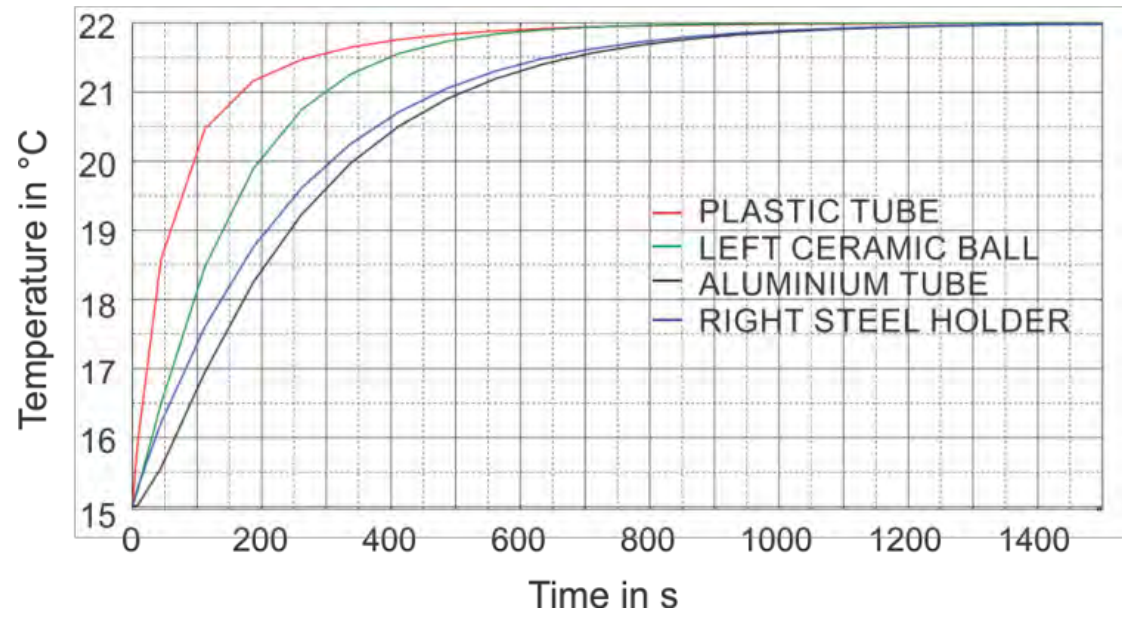

Figure 7: Calculated temperature changes of the most important constructional parts of the standard when simulating the ambient temperature changes from $15^{\circ} \mathrm{C}$ to $22^{\circ} \mathrm{C}$.

\subsection{Experimental measurements at simulated shop floor conditions in the Laboratory for Production Measurement}

In order to confirm theoretical data and simulation results, a thermal experiment was carried out in the Laboratory for Production measurement at University of Maribor. The measurements were performed on the CMM Zeiss UMC 850 (Fig. 8). The length of the ball 
bar standard $1000 \mathrm{~mm}$ and the gauge block $1000 \mathrm{~mm}$ were measured at different environmental temperatures simulating real shop floor conditions. Due to unknown influence of temperature on the measuring device, the measured values were compared with the known parameters of the gauge block. The measurement setup is shown in Fig 9.

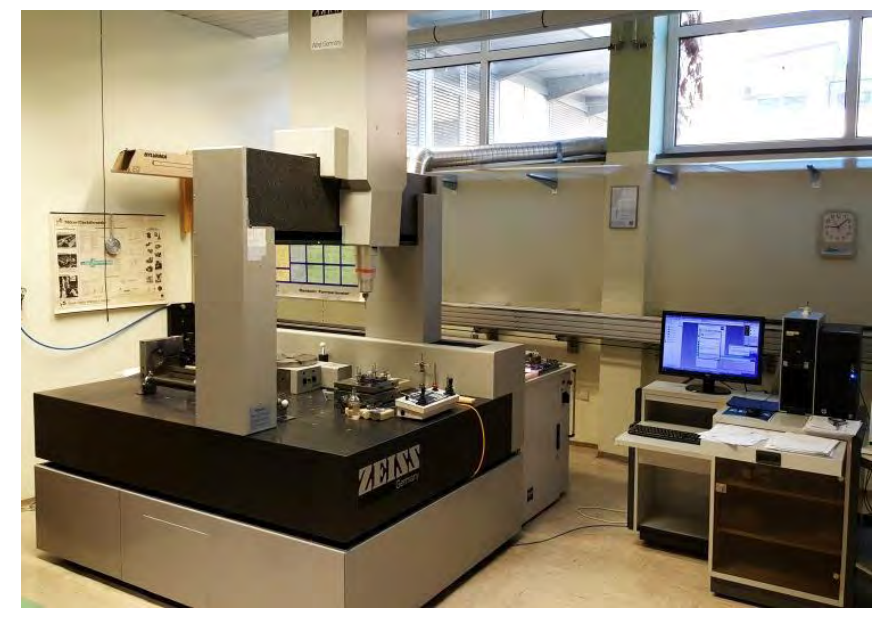

Figure 8: Coordinate measuring machine Zeiss UMC 850.

Lengths of the ball bar standard and the gauge block were measured at environmental temperatures $20^{\circ} \mathrm{C}, 22^{\circ} \mathrm{C}, 24^{\circ} \mathrm{C}$ and $26^{\circ} \mathrm{C}$. The temperatures of the ball bar standard and the gauge block were measured at two ends with precise thermistor contact temperature sensors Zeiss TEMP 10 (expanded uncertainty $U=0.01{ }^{\circ} \mathrm{C}$ ). Quantity $T$ in Table II is the mean temperature of temperatures measured on the ball bar standard and on the gauge block.

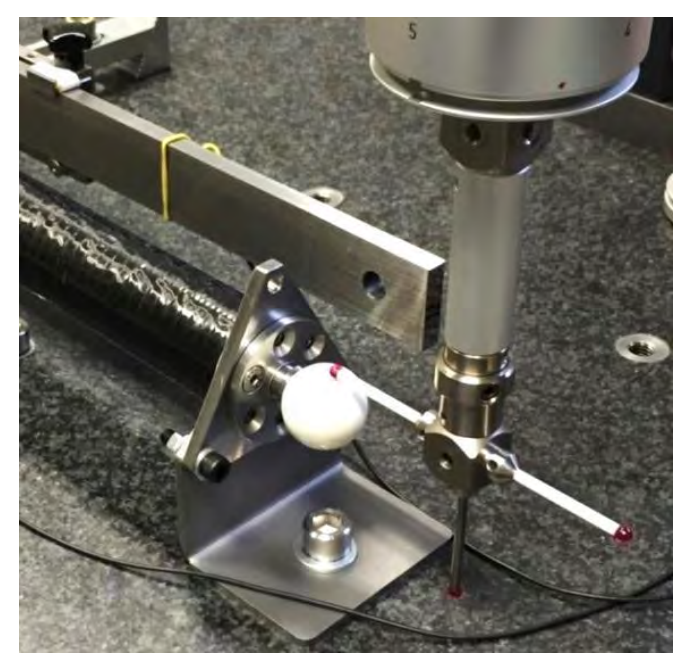

Figure 9: Measuring setup on Zeiss UMC 850.

Table II presents measured lengths $L_{m}$ of the ball bar standard and of the gauge block at $20{ }^{\circ} \mathrm{C}$ compared to the measured lengths $L_{m}$ at other environmental temperatures. Length deviations were calculated for different temperatures other than $20^{\circ} \mathrm{C}$. The measured length of the ball bar standard at $20^{\circ} \mathrm{C}$ is indicated with $L_{\mathrm{B}}$, while the length of the gauge blocks at $20^{\circ} \mathrm{C}$ is indicated with $L_{\mathrm{G}}$. The unknown error of the measuring device is indicated with $e_{\mathrm{d}}$. Eq. (1) shows the calculation of the ball bar standard length $L_{\mathrm{B} 1}$ after the temperature expansion:

$$
L_{\mathrm{B}}+\Delta L_{\mathrm{B}}-e_{\mathrm{d}}=L_{\mathrm{B} 1}
$$

where $\Delta L_{\mathrm{B}}$ is a change of the ball bar length.

Eq. (2) is used for calculating length of gauge block $L_{G 1}$ after the temperature expansion: 


$$
L_{\mathrm{G}}+\Delta L_{\mathrm{G}}-e_{\mathrm{d}}=L_{\mathrm{G} 1}
$$

where $\Delta L_{G}$ is a change of the gauge block length.

Unknown error of the CMM due to heating $e_{\mathrm{d}}$ is expressed as:

$$
e_{\mathrm{d}}=-L_{\mathrm{G} 1}+L_{\mathrm{G}}+\Delta L_{\mathrm{G}}
$$

and is inserted into Eq. (1):

$$
L_{\mathrm{B}}+\Delta L_{\mathrm{B}}+L_{\mathrm{G} 1}-L_{\mathrm{G}}-\Delta L_{\mathrm{G}}=L_{\mathrm{B} 1}
$$

Thermal expansion of the ball standard $\Delta L_{\mathrm{B}}$ is:

$$
\Delta L_{\mathrm{B}}=L_{\mathrm{B} 1}-L_{\mathrm{B}}-L_{\mathrm{G} 1}+L_{\mathrm{G}}+\Delta \mathrm{L}_{\mathrm{G}}
$$

Linear thermal expansion coefficient of the gauge block is well known (the producer states $\left.\alpha=10.8 \cdot 10^{-6}{ }^{\circ} \mathrm{C}^{-1}\right)$. It follows that:

$$
\Delta L_{\mathrm{G}}=L_{\mathrm{G}} \cdot \alpha \cdot \Delta T
$$

By inserting Eq. (6) into Eq. (5) we get the following expansion of the ball bar standard:

$$
\Delta L_{\mathrm{B}}=L_{\mathrm{B} 1}-L_{\mathrm{B}}-L_{\mathrm{G} 1}+L_{\mathrm{G}}+L_{\mathrm{G}} \cdot \alpha \cdot \Delta T
$$

Thus the difference between the length of ball bar standard and gauge block at nominal temperature $T_{n}$ is:

$$
\Delta L=\Delta L_{\mathrm{G}}-\Delta L_{\mathrm{B}}
$$

Table II: Experimental results of measured lengths.

\begin{tabular}{|l|c|r|c|}
\hline & $\boldsymbol{T}\left({ }^{\circ} \mathrm{C}\right)$ & $\boldsymbol{L}_{\boldsymbol{m}}(\mathrm{mm})$ & $\Delta \boldsymbol{L}(\mu \mathrm{m})$ \\
\hline $\boldsymbol{T}_{\boldsymbol{n}}=\mathbf{2 0}{ }^{\circ} \mathbf{C}$ & & & \\
\hline Ball bar standard & 20.08 & 995.7499 & \\
\hline Gauge block & 20.04 & 999.9913 & \\
\hline $\boldsymbol{T}_{\boldsymbol{n}}=\mathbf{2 2}{ }^{\circ} \mathbf{C}$ & & & \\
\hline Ball bar standard & 22.23 & 995.7399 & \\
\hline Gauge block & 22.21 & 1000.0027 & 2.2 \\
\hline $\boldsymbol{T}_{\boldsymbol{n}}=\mathbf{2 4}{ }^{\circ} \mathbf{C}$ & & & \\
\hline Ball bar standard & 23.64 & 995.7377 & \\
\hline Gauge block & 23.63 & 1000.0159 & 2.0 \\
\hline $\boldsymbol{T}_{\boldsymbol{n}}=\mathbf{2 6}{ }^{\circ} \mathbf{C}$ & & & \\
\hline Ball bar standard & 25.84 & 995.7353 & \\
\hline Gauge block & 25.84 & 1000.0373 & 2.1 \\
\hline
\end{tabular}

Results in Table II indicate that the length difference between the ball bar standard and the gauge block at different temperatures is constantly around $2 \mu \mathrm{m}$. Since no correlation between temperature and the ball bar standard expansion was shown, we can assume that the deviations are the consequence of random measurement errors. After getting satisfying laboratory results we have continued our experiment measurements in the industrial environment.

\subsection{Measurements in uncontrolled industrial environment}

We have made measurements in harsh environment of the shop floor. The research was performed in collaboration with companies EMO Orodjarna and Gorenje Orodjarna (Fig. 10). The results of the length measurements of the ball bar standard at different temperatures are shown in Table III. 


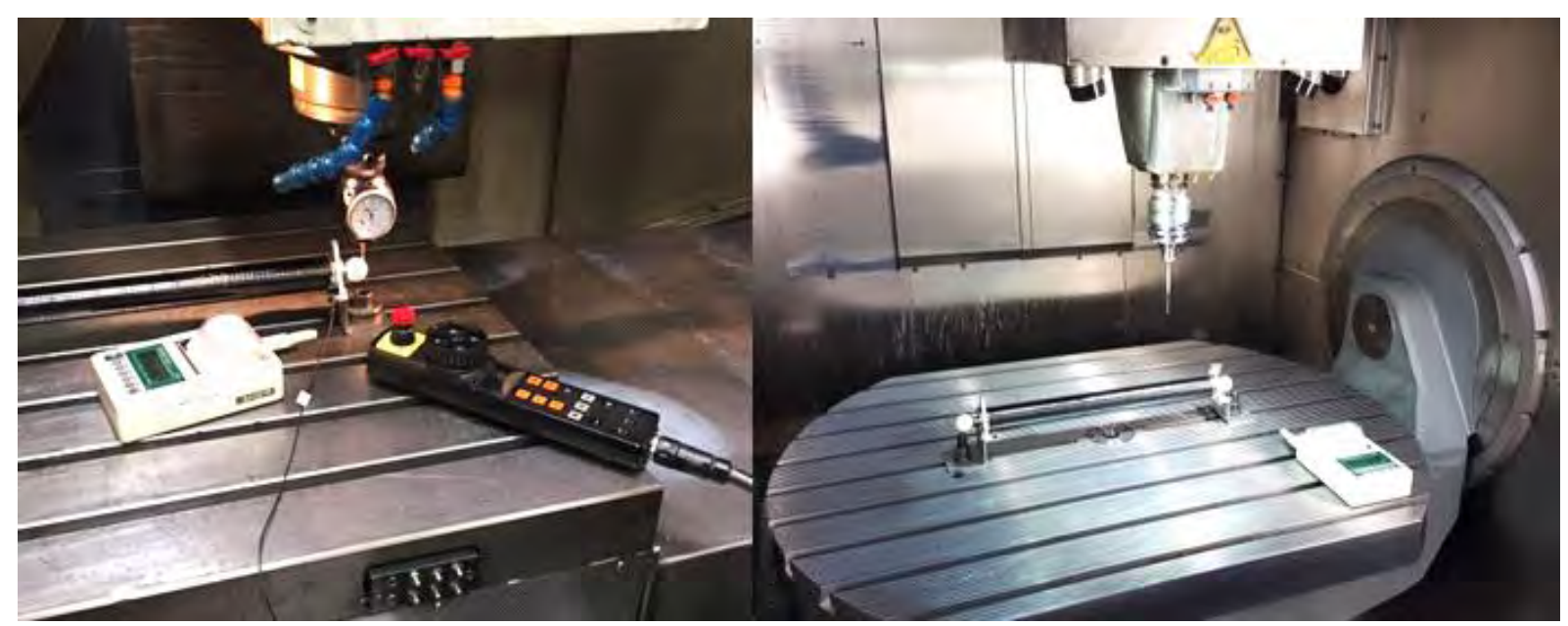

Figure 10: Measurement setups in EMO Orodjarna (left) and in Gorenje Orodjarna (right).

Results in Table III show that measured length differences of the ball bar standard at different temperatures are very low. Measurements in Gorenje Orodjarna contain temperature corrections. Based on the achieved measurement results it can be concluded, that no significant linear regression due to temperature changes is present. Therefore, it is quite obvious, that the deviation of $2 \mu \mathrm{m}$ is a consequence of random measurement errors.

Table III: Measurement results in the production floor.

\begin{tabular}{|c|c|}
\hline $\boldsymbol{T}\left({ }^{\circ} \mathrm{C}\right)$ & $\boldsymbol{L}_{\boldsymbol{m}}(\mathrm{mm})$ \\
\hline 26.7 & 995.72155 \\
\hline 25.2 & 995.72235 \\
\hline 24.2 & 995.72038 \\
\hline 24.3 & 995.72076 \\
\hline 23.5 & 995.72113 \\
\hline 22.2 & 995.72020 \\
\hline
\end{tabular}

\section{CONCLUSION}

The project aimed for assuring traceability of in-process measurements EMRP TIM [5] is already in the conclusion phase. Different standards were designed, manufactured and calibrated. Calibration results are being verified by interlaboratory comparison in the last phase of the project. Very important part of the project is also development and validation of procedures for calibrating and verifying machine tools under harsh environmental conditions. The experimental phase of verifying standards and procedures is being concluded at the moment.

The presented standard was produced by three Slovenian unfunded industrial partners in the project: Gorenje Orodjarna, EMO Orodjarna and Veplas. After concluding testing and verification, it was calibrated in the Laboratory for Production Measurement at the University of Maribor.

The validation process for the standard and verification procedures consists basically of three parts: analytical and numerical calculations by using available knowledge, experimental verification in the laboratory, and tests in real shop floor conditions in two production environments. One of the final goals of this validation phase was to determine uncertainty of measurement in calibration and verification $[11,14]$. It is expected that the contribution of short term and long term geometrical stability of the standards will have no significant influence on the total measurement uncertainty. 
Theoretical part of the validation process and the experimental part in the laboratory have already been concluded, while tests in industrial conditions are still to be continued in a form of test calibrations. After finishing test calibrations, the standards and procedures will be offered to European industrial users for verification of their machine tools that are being used and 3D measuring devices in industry.

\section{ACKNOWLEDGEMENT}

The authors would like to acknowledge funding of the presented research within the European Metrology Research Programme (EMRP) in the Joint Research Project IND62 TIM. Furthermore, fruitful professional discussions within the research group, especially with National Physical Laboratory (NPL) and Phisikalisch Technische Bundesanstalt (PTB), are highly appreciated.

\section{REFERENCES}

[1] Koren, R.; Palčič, I. (2015). The impact of technical and organisational innovation concepts on product characteristics, Advances in Production Engineering \& Management, Vol. 10, No. 1, 27-39, doi:10.14743/apem2015.1.190

[2] Mgwatu, M. I. (2013). Integrated approach for optimising machining parameters, tool wear and surface quality in multi-pass turning operations, Advances in Production Engineering \& Management, Vol. 8, No. 4, 209-218, doi:10.14743/apem2013.4.168

[3] Cus, F.; Zuperl, U. (2013). Control strategy for assuring constant surface finish by controlling cutting forces, Transactions of FAMENA, Vol. 37, No. 3, 41-52

[4] Ostasevicius, V.; Gaidys, R.; Dauksevicius, R.; Mikuckyte, S. (2013). Study of vibration milling for improving surface finish of difficult-to-cut materials, Strojniski vestnik - Journal of Mechanical Engineering, Vol. 59, No. 6, 351-357, doi:10.5545/sv-jme.2012.856

[5] Klancnik, S.; Ficko, M.; Balic, J.; Pahole, I. (2015). Computer vision-based approach to end mill tool monitoring, International Journal of Simulation Modelling, Vol. 14, No. 4, 571-583, doi:10.2507/IJSIMM14(4)1.301

[6] Wendt, K. (2013). IND62 TIM - Traceable in-process dimensional measurement, EMRP JRP protocol, PTB Braunschweig

[7] Schwenke, H.; Knapp, W.; Haitjema, H.; Weckenmann, A.; Schmitt, R.; Delbressine, F. (2008). Geometric error measurement and compensation of machines - An update, CIRP Annals Manufacturing Technology, Vol. 57, No. 2, 660-675, doi:10.1016/j.cirp.2008.09.008

[8] ISO 230-1 (2012). Test code for machine tools - Part 1: Geometric accuracy of machines operating under no load or finishing conditions, ISO Copyright Office, Geneva

[9] Mijuskovic, G.; Krajnik, P.; Kopac, J. (2013). Improvement of positional accuracy of precision micro milling center using pitch error compensation, Technical Gazette, Vol. 20, No. 4, 629-634

[10] Cuesta, E.; Mantaras, D. A.; Luque, P.; Alvarez, B. J.; Muina, D. (2015). Dynamic deformations in coordinate measuring arms using virtual simulation, International Journal of Simulation Modelling, Vol. 14, No. 4, 609-620, doi:10.2507/IJSIMM14(4)4.311

[11] Acko, B.; Klobucar, R.; Acko, M. (2015). Traceability of in-process measurement of workpiece geometry, Procedia Engineering, Vol. 100, 376-383, doi:10.1016/j.proeng.2015.01.381

[12] Acko, B.; Milfelner, M. (2014) Temperature-invariant material standard for monitoring performance of machine tools, Proceedings of the $18^{\text {th }}$ International Research/Expert Conference TMT 2014, 297-300

[13] Mudronja, V.; Katic, M.; Simunovic, V. (2014). Realization of the highest level of traceability in Croatian National Laboratory for length, Transactions of FAMENA, Vol. 38, No. 1, 37-44

[14] ISO/TR 230-9 (2012). Test code for machine tools - Part 9: Estimation of measurement uncertainty for machine tool tests according to series ISO 230, basic equations, ISO Copyright Office, Geneva

[15] Acko, B.; Sluban, B.; Tasic, T.; Brezovnik, S. (2014). Performance metrics for testing statistical calculations in interlaboratory comparisons, Advances in Production Engineering \& Management, Vol. 9, No. 1, 44-52, doi:10.14743/apem2014.1.175 